\title{
Indian Literature, Multiculturalism and Translation
}

Guru Charan Behera

\begin{abstract}
Translation plays a significant role, explicit or implicit, deliberate or spontaneous in the interlingual, intercultural communication between the people of India, as well in the construction of multilingual, multicultural Indian Literature. It negotiates the power relations between various cultural formations and different linguistic mediums as a means of communication and as a language of translation, contributing to the egalitarian process by countering the hierarchical relationships between languages and cultures, reclaiming disappearing texts and cultures, and releasing knowledge from the control of a few. The paper addresses these complex interconnected issues of Indian Literature, multiculturalism and translation.
\end{abstract}

\section{India as a Multicultural Space}

India is a multicultural space accommodating many races, castes, languages, religions and cultures. These exist paradoxically as distinct and, at the same time, interconnected, even overlapping, identities, at multiple levels. India can be described as a nation of nations, a land of many Indias, variously imagined by these communities/collectivities through various cultural forms and expressions. Out of this scenario emerge multilingual forms of Indian literature, and in this translation plays a role that can be explicit or implicit, deliberate or spontaneous. The aim of this paper is to discuss how translation participates in these complex interrelations and negotiates the power relationships between these various socio-cultural forces and different linguistic mediums, such as the choice of bhashas vis-a-vis English as the language of translation. 


\section{Indian Literature}

Indian literature is an expression of the vital plurality and productive diversity of our nation. Community-states in India have no well-defined boundaries; they cross each other's frontiers. In many cases, languages are not confined to the geographical boundaries of particular states; languages contain many variations and dialects and share a number of features. States have a mixed population speaking different languages. When members of these communities communicate with each other, they often have to speak different mixed varieties of languages, so people inside their state as well as outside are constantly engaged in translation. India, thus, is a land of "translating consciousness" (Devy 1993: 135).

A literary trend in a particular language can go beyond the boundaries of the given language to establish historical, thematic, and stylistic correspondence with literatures in other Indian languages. The Bhakti Poetry movement at one time spread across the regional and linguistic barriers of the country. There are writers who speak and write in many languages and readers who understand and enjoy literatures in more than one language. In a single text there can be multilingual situations, or polyphony, or the use of many languages. In the plays of Kalidas Sanskrit, Prakrit, and Magadhi were used with ease and naturalness and the audience could understand and enjoy the linguistic shifts within a single work. Literary creations have been appropriated and transformed into new incarnations in geographically and temporarily distant spaces. Texts have been transcreated, translated, adapted, imitated, and sometimes, interpreted and circulated in new literary constructs. Following the decline of Sanskrit as the central language of creative expression the languages of various regions of India emerged as the mediums of knowledge, and literature. Knowledge that until then had been confined to a few individuals was liberated, to be made available to common people. Translation played a significant role in the diversification and dissemination of knowledge and also in the evolution and enrichment of Indian languages and literatures. A number of Sanskrit texts were translated into regional languages, and 
took different interpretations and forms. The linguistic and cultural heterogeneity of Indian society as both a reality and the norm was recognized and established. Translation helps expose Indian writers writing in one language to the styles, techniques and experimentations in the literatures of other languages, so that they can use these creatively in their own writings. New trends in literature have been facilitated by translation activities.

\section{Multiculturalism}

Multiculturalism implies a multiplicity of contesting cultural voices that are allowed to articulate the imagined community of the nation on their own terms. As such, it should be seen as a contestation of mono-culturalism, the impulse to impose one cultural order on all sections of society. Multicultural India thus cannot be reduced to a single ideological concept; instead, when the sharply contrasting cultural constructs of the national imaginary are set in dialogic relation there occurs an infinitely complicated aporia that cannot be resolved in the name of ideological consistency or logical unity (Derrida 1982: 43-44). It must be accepted that Indian identity is a ceaseless play, a coming together and moving apart, of different cultures.

Multiculturalism inhabits a plane space, not a hierarchical space. This can be explained in the light of postmodern theory. Postmodern theory, in theorizing plane space, attacks foundational theory, or essentialist philosophy, that supports mono-culturalism. Francois Lyotard defines, postmodernism as "incredulity towards metanarrative" that displaces the discourse of metanarrative or grand narrative and argues for a cultural space that is populated by little narratives (1993: 3). These narratives are governed by their own constituting rules and are not dependent on extra-narrational foundational rules for articulation. Such discursive forms are not arranged in a hierarchical order; they are allowed to flourish alongside of each other, on a plane space of cultural autonomy. Another term Lyotard has used is differend, which denotes "a case of conflict between two parties that can not be resolved for lack of a 
rule of judgment applicable to both arguments" (1988: xi). This is closer to what Derrida implies by aporia, disallowing the formation of a master narrative and blocking the cultural process of marginalization.

To describe postmodern multicultural space Gilles Deleuze and Felix Guattari develop the concept of rhizome. A rhizome is any plant (like grass) whose root system spreads horizontally on the ground; as the plant grows outward and across it can grow to cover the whole land mass. It is a figure of non-hierarchical, structureless, open system. It is apposed to the aborescent, the tree, which suggests the image of a root that grounds textual (and cultural) complexes in a foundational matrix in order to uphold a unified, centered and hierarchical system that characterizes the narratives of modernity.

Multiculturalism has two implications. First, it presents culture as a site of contestation and competition, in which the periphery is engaged in conflict with the centre, setting off the free play of various elements. American critic Wahneema Lubiano, in her essay "Like Being Mugged by a Metaphor: Multiculturalism and State Narratives," calls this phenomenon radical multiculturalism, in which contestation is the driving force. Second, there is historical multiculturalism, which aims at recovering lost historical, cultural voices, as discussed by Ronald Takaki, in his book A Different Mirror (1993). The continuous deployment of the force of translation will resist the structure of domination and marginalization, foreground little narratives, and retrieve the lost historical cultural voices; it thus can serve the purposes of both types of multiculturalism. Though multiculturalism conceives cultures as autonomous, it opens up a space for constant "negotiation" between them and even facilitates the process of hybridization. Between cultural forms there is the clearing in which interpenetration takes place. Translation operates in this clearing, in the "in-between" space, as an aid to and product of this negotiation process. 


\section{Translation}

Translation is an egalitarian process that engineers the plane space. It frees the knowledge system from the possession of a few individuals, transfers the text into different domains, and gives it new linguistic and cultural incarnations. Translation is not concerned with the transfer of meaning; it transforms a text, and, in the process, may transform the meaning, which the target language culture often influences and determines. Derrida calls translation "a regulated transformation" (1981: 20). Walter Benjamin, in his "The Task of the Translator", argues that instead of simply transporting the meaning of the original, a translation must "lovingly and in detail, incorporate the original's mode of signification, thus making the original and the translation recognizable as fragments of a greater language, just as fragments are parts of a vessel" (1969: 78).These fragments are not expected to be identical to each other. The original presents itself as univocal, complete, identical to itself; but it is translation which brings out the multiple possibilities of the original that can be transformed into various cultural forms and expressions. For Benjamin a translation represents the "afterlife" of the work, which Tejaswini Niranjana interprets as "the continued life of the text rather than afterlife to follow its death" (1992: 134). In translation the original finds new life, grows, matures, is supplemented. If one aspect of multiculturalism is the reclamation of disappearing cultures, translation serves its purpose by retrieving a text and ensuring its "continued life". For instance, the Ramayana and the Mahabharata, translated into a number of languages, have been transformed and converted into target language cultural texts and live their "afterlife". Another point to be noted here is that translation is an attempt to bring the languages engaged in the process of translation to the same level, thus countering the hierarchical relationship between them, such as between Sanskrit and bhashas, English and bhashas, or between different bhashas.

\section{Translation in India}

In India English has become the dominant mode of translation. Indian writers vie with each other to get their works translated into English, both as a status symbol and in their 
eagerness to reach out to western audiences. Many translators also use English in imitation of standard British English, to be understood and appreciated by western readers, ignoring the presence in India of a sizeable number of English knowing readers, who could form the target audience. As a result, these translations tend to gloss over, even exclude, many local peculiarities and cultural specificities of the bhasha text. This is a neocolonial tendency, a replication of the past colonial hegemony. The result is not a real representation of Indian culture; oftentimes, it turns out to be a distorted representation. In this context it can be pointed out that there is no need to ignore various cultural features of Indian society or gloss over Indian cultural terms and expressions; they can be used creatively to enrich the English language and widen the multicultural scope of Indian English.

Even A.K. Ramanujan has given an English rendering of place names. In Speaking of Shiva Basavanna's Kudala Sangam becomes, 'Lord of the Meeting Rivers', Mahavinayaka's Mallikarjuna becomes 'Lord White as Jasmine', Allama Prabhu's Guheswar, 'Lord of the Caves'. Ramanujan's explanation in this regard is significant:

I have [...] taken the liberty of translating literally into English the name of Siva here, Chennamallikarjunna. For such names carry aspect and attributes of Siva. Further, such proper nouns, if as they are in the English translation, are inert and cannot participate in the poems as they do in the originals. (1973: 193)

But the names of gods in one language cannot be expressed in another language in summary forms, as they form an integral part of the source language culture. Indeed, in his translation of U.R.Ananthamurthy's Samskara Ramanujan has used many Indian expressions and Indianized English expressions.

In the English translation of Oriya novelist Gopinath Mohanty's Paraja, Bikram Keshari Das has edited out many descriptions of cultural forms of the Paraja tribe, such as tribal songs, dances and rituals. As a result, the translation does not 
adequately represent the original and its culture. This kind of translation into English, more precisely into standard British English, has the danger of ignoring the linguistic, literary, and cultural significances of the source language text, equating language with nation and equating English with India, relegating the solid presence of multilingualism and multiculturalism to the background. The nation might turn out to be an English-educated metropolitan construct. To counter this, the type of English we need as a language of translation is one that incorporates Indian linguistic and cultural expressions and reorients English forms to construct an Indian idiom. It should be restructured English that goes beyond the boundaries of domination, even to prevent it, to a certain extent, from being a language of the urban middle class. Indian English can become a language of various forms.

In representing and translating typical Indian situations and expressions Raja Rao in his novel Kanthapura (1938) has made pioneering efforts. In his foreword to Kanthapura Rao states:

One has to convey in a language that is not one's own the spirit that is one's own [...]. We are instinctively bilingual, many of us writing in our own language and in English. We cannot write like the English. We should not. We cannot write only as Indians. [...] The tempo of Indian life must be infused into our English expression, even as the tempo of American or Irish life has gone into making of theirs.(5-6)

In the novel he has Indianized some English words: 'younglings', 'feedless', 'milkless', 'clothless' (18), 'vengefulness' (76), 'sobless' (91), 'clayey' (92), 'unmuddled' (95), 'seeable' (127), 'tongued' (134). Some very unusual transferred epithets translate typically Indian situations and idioms: 'gaping sacks' (25), 'sobbing lantern', 'frothing milk-pot' (32), 'pungent tamarind', 'suffocating chillies', 'lolling bells and muffled bells' (45), 'bellied boulders', 'dallying drain' (87) 'winkless night', 'wakeful night' (125), 'thunderless rain' (143). Many Indian words are retained in the text, without any attempt to translate them into English equivalents: 'patwari' (9), 'sari' (13), 'vidwan' (15), 'annas', 
'banya' (24), 'charka' (250), 'taluk' (27), 'khir', 'dal' (28), 'chutney' (29), 'pheni' (32), 'happalam' (42), 'ragi', 'kumkum' (45), 'prayaschita' (46), 'dhoti' (56), 'mandap' (67), 'panchayat' (77), 'laddu' (85), 'vakils' (92), 'maidan bazzar' (93), 'cummerbund' (119).

In the sentence "Nobody who has eyes to see and ears to hear will believe in such a crow-and-sparrow story" Rao prefers "crow-and-sparrow" to its English equivalent "cock and bull story". Translated expressions like "Our granary is empty as a mourning house" (25), "I swear he would have done had not the stream run the way it did" (27), "....let your family creepers link each other" (29), "....the youngest is always the holy bull" (39), "Our hearts are squeezed like a wet cloth" (175) point to typical Indian usages, idioms, rhetoric and belief systems.

He has also tried to bring English closer to the syntactic structure of Indian language with the inversion of verb and subject in the sentences like "Kanthapura [...] high on the ghat is it [...] up the Malabar coast is it [...] (7), "Kenchamma [...] Great and bounteous is she; never has she failed us in our grief' (8), "And he can sing too, can Jayaramachar" (16), "I tell you he was not a bad man, was Bhatta" (32), "Then he goes, Moorthy, to Pandit Venkateshia" (26).

Salman Rushdie's position is similar to Raja Rao's:

English, no longer an English language, grows from many roots, and those whom it once colonized are carving out large territories within the language for themselves (London Times, July 3, 1982).

In this article Rushdie refers, with admiration, to G.V. Desani, who showed "how English could be bent and kneaded until it spoke in an authentically Indian voice". In Midnight's Children, while words like 'writery', 'looker-after' 'writing-shifting' are Indian derivations of English words, 'chutnification' is an example of English derivation of Indian words. Many such hybrid expressions used in the novel demonstrate the strength and creativity of India. His use of the term 'Dung Goddess' for Lotus-seated 
Goddess Lakshmi, however, does not seem appropriate, for it is not from dung but from mud or swamp or slush that lotuses grow.

Another way to reverse this one-way traffic, or check this lopsided development of translation praxis is for English texts to be translated into bhashas in large number. There should be extensive translation of bhasha texts into other bhashas to help construct an interrelated multicultural space. This could be possible by liberating ourselves from the metropolitan notion of a unified space, governed by English or any regional language. Those translated are likely to subjugate the rest that remain untranslated and the rest of local knowledge. To counter the asymmetrical relations of power between various languages and texts in India more and more interlingual translation should be carried out.

Hence, apart from the development and sharpening of Indian English as the language of translation, the promotion of extensive heterographic translation - the translation between various languages, bhashas and English and between bhashas - is perhaps one way to achieve linguistic decentralization in a multilingual nation like India and engineer the plane space of multiculturalism. Translations as a channel of communication between linguistic communities help construct an interlingual and intertextual space for bhashas and their literatures to inhabit and to use for their mutual enrichment. Translation also helps to expand the interconnections between bhasha literatures and to contribute to the mosaic of Indian Literature.

\section{Works Cited}

Benjamin, W. 1969. "The Task of the Translator.” In Illuminations. Trans. H. Zohn, ed. H. Arendt. New York: Schocken Books.

Deleuze, G. and F. Guattari. 1983. A Thousand Plateaus: Capitalism and Schizophrenia. Trans. R. Hurley, M. Seem and H. R. Lane. Minneapolis: University of Minnesota Press. 
Derrida, J. 1981. Positions. Trans. A. Bass. Chicago: University of Chicago Press.

Derrida, J. 1982. Margins of Philosophy. Trans. A. Bass. Chicago: University of Chicago Press.

Devy, G.N. 1993. In Another Tongue: Essays on Indian Literature in English. Bangalore: Macmillan India.

Lubiano, W. 1996. "Like Being Mugged by a Metaphor: Multiculturalism and State Narratives". In Mapping Multiculturalism, ed. A. F. Gordon and C. Newfield. Minneapolis: University of Minnesota Press.

Lyotard, J.F. 1988.The Differend: Phrases in Dispute. Trans. G. Van Dan Abbeele. Minneapolis: University of Minnesota Press.

Lyotard, J.F. 1993 (1984). The Postmodern Condition: A Report on Knowledge. Trans. G. Bennington and B. Massumi. Minneapolis: University of Minnesota Press.

Niranjana, T. 1992. Siting Translation. Hyderabad: Orient Longman.

Ramanujan, A.K. 1973. Speaking of Siva. New Delhi: Penguin.

Rao, R. 1970 [1938]. Kanthapura. New Delhi: Orient Paperback.

Rushdie, S. 1982. Midnight's Children. London: Picador.

Takaki, R. 1993. A Different Mirror: A History of Multicultural America. Boston: Little, Brown and Co. 